\title{
The interaction effects between TLR4 and MMP9 gene polymorphisms contribute to aortic aneurysm risk in a Chinese Han population
}

\author{
Tan Li ${ }^{1,2}$, Xu Zhang ${ }^{3}$, Liang Sang ${ }^{1}$, Xin-tong Li', Hai-yang Sun ${ }^{2}$, Jun Yang ${ }^{2}$ and Yuan Yuan ${ }^{1 *}$ (1)
}

\begin{abstract}
Background: A cross-talk between Toll-like receptor 4 (TLR4) and matrix metalloproteinase 9 (MMP9) plays a vital role in aortic pathophysiology. The objective of this study was to evaluate the interactions between TLR4 and MMP9 polymorphisms in the risk of aortic aneurysm (AA) and its subtypes.

Methods: KASP method was used to detect polymorphisms of TLR4 (rs11536889 and rs1927914) and MMP9 (rs17576) in $472 \mathrm{AA}$ patients and 498 controls. According to location and size, AA patients were further classified into abdominal AA (AAA), thoracic AA $(T A A)$, and large $A A(>5.0 \mathrm{~cm})$, small $A A(\leq 5.0 \mathrm{~cm})$, respectively.

Results: The significant interaction effect of TLR4rs1927914 with MMP9rs 17576 polymorphisms was observed for the risk of TAA ( $\left.P_{\text {interaction }}=0.038, \mathrm{OR}=6.186\right)$ and large AA $\left(P_{\text {interaction }}=0.044, \mathrm{OR}=5.892\right)$. There were epistatic effects between TLR4rs1927914 and MMP9rs17576 polymorphisms on the risk of overall AA, AAA, TAA and large AA when they were present together. Moreover, the cumulative effects of the pairwise interaction TLR4rs1927914-MMP9rs17576 were associated with an increased risk of overall AA $\left(P_{\text {trend }}=0.032\right)$ and AAA $\left(P_{\text {trend }}=0.031\right)$.

Conclusions: The novel interaction between TLR4rs1927914 and MMP9rs17576 polymorphisms could increase the risk of AA disease or its subtypes by exerting epistatic and cumulative effects.
\end{abstract}

Keywords: Toll-like receptor 4, Matrix metalloproteinase 9, Aortic aneurysm, Polymorphism, Interaction

\section{Background}

Aortic aneurysm (AA) is a life-threatening complex disease with uncertain etiology and can occur in the abdominal or thoracic section of aorta. Although abdominal aortic aneurysm (AAA) and thoracic aortic aneurysm (TAA) have heterogeneity in their inheritance, incidence and distribution along aorta, they share some similar pathological states and histological phenotypes, including inflammatory cell infiltration and extracellular matrix (ECM) degradation $[1,2]$. AA size has been reported to be an important independent predictor of perioperative morbidity and mortality, and special attention is deserved once maximal aortic diameter

\footnotetext{
* Correspondence: yuanyuan@cmu.edu.cn.

'Tumor Etiology and Screening Department of Cancer Institute and General Surgery, The First Hospital of China Medical University, No.155 Nanjing Bei Street, Heping District, Shenyang, Liaoning Province, People's Republic of China110001

Full list of author information is available at the end of the article
}

approaches the $5.0-5.5 \mathrm{~cm}$ threshold, which is perceived as an abrupt transition and increases the rupture risk of an aneurysm [3, 4]. There are several confounding factors associated with AA, including age, gender, hypertension and dyslipidemia $[5,6]$. As for diabetes, whether it has a protective or risk effect on AA is far from definitive $[7,8]$. Accumulating evidence supports an important role of genetic susceptibility in the initiation and development of AA. The activity and function of genes can be modulated by single nucleotide polymorphisms (SNPs), which may have impacts in amino acid substitutions changing protein function, in coding regions disturbing mRNA stability sequences or in promoter regions altering transcription factor binding motifs [9]. Although a large number of literatures have studied the association of genetic polymorphisms with AA, the responsible genes remain largely unidentified.

(c) The Author(s). 2019 Open Access This article is distributed under the terms of the Creative Commons Attribution 4.0 International License (http://creativecommons.org/licenses/by/4.0/), which permits unrestricted use, distribution, and 
Inflammation and degradation of aortic media are considered mainly responsible for aortic expansion and aneurysm formation [10]. Toll-like receptor 4 (TLR4) is one of the most well-characterized inflammation-related molecules, and its signaling plays a key role in triggering inflammatory response in the aortic wall $[9,10]$. A growing number of cell and animal experiments have revealed the importance of TLR4 pathway in AA formation [10-12]. TLR4 dysfunction caused by SNPs may change the ligand binding and balance between pro- and anti-inflammatory cytokines, and studies have demonstrated a functional significance of TLR4 polymorphisms in modulating the risk of some inflammatory diseases [13-15]. However, there were lacking researches on the relationship between TLR4 polymorphisms and AA risk. Recent studies reported that TLR4 took part in vascular homeostasis through a cross-talk with other signaling pathways, including ECM degradation pathway $[11,16]$. Because of its capacity of degrading multiple extracellular components in aortic wall, matrix metalloproteinase 9 (MMP9) has been involved in aneurysm formation [2, 17]. A number of MMP9 polymorphisms have been investigated to discuss their associations with the risk of TAA or AAA, but often limited to a single locus, which seems insufficient as the genetic basis in predicting the risk of AA. However, multigene SNP-SNP interactions may amplify the main effect of individual SNP in complex diseases and enhance the predictive power [18].

Consequently, in this study, we firstly focused on the two- and three-dimensional interactions among TLR4 and MMP9 polymorphisms for their potential roles in susceptibility to AA and its subtypes stratified by location and size. We hoped to find the combined effects of gene-gene polymorphisms that might predict the risk of this disease and provide the evidence for the early detection of AA.

\section{Methods}

\section{Study population}

The study was approved by the Ethics Committee of the First Hospital of China Medical University (Shenyang, China). Written informed consent was obtained from each participant. A total of 472 AA patients (including 212 AAA patients, 216 TAA patients, 44 TAA combined AAA patients) and 498 healthy controls were recruited from the First Hospital of China Medical University between September 2016 and November 2017. The patients were enrolled from the cardiac or vascular surgery department of our hospital in which hospitalized patients received the treatment of AA. The control subjects were recruited from the physical examination center of our hospital and frequency-matched to AA cases on the basis of gender and age ( \pm 5 years). That means an individual in the control group can be matched to AA case so long as it has the same gender and neither the age differences between the control and case are more than 5 years. The diagnosis of all patients was based on the computed tomography angiography (CTA). Exclusion criteria included the subjects with coronary heart disease, congenital heart disease, severe vascular stenosis, autoimmune disease, severe organ failure, infectious disease, hematological system disease and malignant tumor. Available maximal aortic diameter of AA patients was obtained from CTA and all participants had their baseline characteristics recorded, as shown in Table 1. According to the maximal aortic diameter, AA patients were further classified into large AA $(>5.0 \mathrm{~cm})$ and small AA $(\leq 5.0 \mathrm{~cm})$. A $5-\mathrm{ml}$ fasting venous blood sample was taken from each subject for DNA isolation.

Hypertension was defined as having a systolic blood pressure $(\mathrm{SBP}) \geq 140 \mathrm{mmHg}$ and/or having a diastolic blood pressure $(\mathrm{DBP}) \geq 90 \mathrm{mmHg}$ and/or being under antihypertensive treatment. Diabetes was defined as fasting serum glucose (FPG) $\geq 7 \mathrm{mmol} / \mathrm{L}$ and/or being on treatment for diabetes. Dyslipidemia was defined as serum total cholesterol $(\mathrm{TC}) \geq 6.22 \mathrm{mmol} / \mathrm{L}$, or triglyceride (TG) $\geq 2.26 \mathrm{mmol} / \mathrm{L}$, or high-density lipoprotein cholesterol $(\mathrm{HDL}-\mathrm{C})<1.03 \mathrm{mmol} / \mathrm{L}$, or low-density lipoprotein cholesterol $(\mathrm{LDL}-\mathrm{C}) \geq 4.14 \mathrm{mmol} / \mathrm{L}$ and/or under taking hypolipidemic drugs.

Table 1 Baseline characteristics of the study participants

\begin{tabular}{|c|c|c|}
\hline \multirow[t]{2}{*}{ Variable } & $\mathrm{CON}$ & AA \\
\hline & $n=498$ & $n=472$ \\
\hline Age, years & $60.55 \pm 12.61$ & $60.97 \pm 12.62$ \\
\hline Male, n (\%) & $355(71.3 \%)$ & $342(72.5 \%)$ \\
\hline Hypertension, n (\%) & $214(43.0 \%)$ & $327(69.3 \%)^{*}$ \\
\hline $\mathrm{SBP}, \mathrm{mmHg}$ & $136.42 \pm 20.61$ & $153.33 \pm 26.61^{*}$ \\
\hline $\mathrm{DBP}, \mathrm{mmHg}$ & $78.70 \pm 12.06$ & $86.89 \pm 16.48^{*}$ \\
\hline Diabetes, n (\%) & $55(11.0 \%)$ & $125(26.5 \%)^{*}$ \\
\hline $\mathrm{FPG}, \mathrm{mmol} / \mathrm{L}$ & $5.67 \pm 1.49$ & $6.36 \pm 1.88^{*}$ \\
\hline Dyslipidemia, n (\%) & 203(40.8\%) & $262(55.5 \%)^{*}$ \\
\hline $\mathrm{TC}, \mathrm{mmol} / \mathrm{L}$ & $4.56 \pm 1.10$ & $4.96 \pm 0.91^{*}$ \\
\hline $\mathrm{TG}, \mathrm{mmol} / \mathrm{L}$ & $4.56 \pm 1.10$ & $4.96 \pm 0.91^{*}$ \\
\hline $\mathrm{HDL}-\mathrm{C}, \mathrm{mmol} / \mathrm{L}$ & $1.29 \pm 0.33$ & $1.10 \pm 0.37^{*}$ \\
\hline $\mathrm{LDL}-\mathrm{C}, \mathrm{mmol} / \mathrm{L}$ & $2.87 \pm 0.95$ & $3.14 \pm 0.78^{*}$ \\
\hline \multicolumn{3}{|l|}{ AA type } \\
\hline $\mathrm{AAA}(\%)$ & - & 212(44.9\%) \\
\hline TAA(\%) & - & $216(45.8 \%)$ \\
\hline TAAA(\%) & - & $44(9.3 \%)$ \\
\hline Max. aortic diameter, cm & - & $5.03 \pm 1.48$ \\
\hline$>5.0 \mathrm{~cm}$ & - & $160(33.9 \%)$ \\
\hline$\leq 5.0 \mathrm{~cm}$ & - & $272(57.6 \%)$ \\
\hline Missing & - & $40(8.5 \%)$ \\
\hline
\end{tabular}

${ }^{*} P<0.05$, AA vs. CON; $A A$ aortic aneurysm, CON control 


\section{SNP selection and genotyping assay}

According to previous description [19], we adopted a two-step method to select tag-SNPs for the genes of interest. In brief, tag-SNPs were chosen in the combinations provided by data from the HapMap database (http://www.HapMap.org) and Haploview software 4.2 (http://www.broadinstitute.org/mpg/haploview). Then, SNPinfo Web Server (https://snpinfo.niehs.nih. gov/) was used to predict their potential functions. Finally, two TLR4 SNPs (rs11536889 in the 3'-untranslated region (UTR), rs1927914 in the promoter region) and one MMP9 SNP (rs17576 in the exon 6) were chosen in this study.

Genomic DNA of each subject was extracted from a blood clot by a routine phenol-chloroform approach and then diluted to a working concentration of $50 \mathrm{ng} / \mu \mathrm{L}$ for genotyping. All samples were randomly placed in the 384-well plates and blinded for disease status. SNP genotyping was performed by Baygene Biotechnology Company Limited (Shanghai, China) using the KASP method with SNPLine platform (LGC, United Kingdom). Additionally, we randomly selected samples for repeated assays and the results were $100 \%$ consistent.

\section{Statistical analysis}

All the statistical analyses were performed with SPSS 17.0 software (SPSS Inc., Chicago, IL, United States). Differences of baseline characteristics between case and control groups were estimated by independent-sample t-test or $\chi^{2}$ test as appropriate. The two- or three-dimensional SNP-SNP interaction effects were assessed using multivariate logistic regression analysis by comparing the model that only involved the main effects with the full model that also contained the interaction term. Associations were calculated by odds ratios (ORs) and 95\% confidence intervals (95\% CIs) with adjustments for age, gender, hypertension, diabetes and dyslipidemia. As for the cumulative effect, linear regression model was used to explore the trends with an increasing number of risk genotypes. A two-sided $P<0.05$ was considered statistically significant. The Bonferroni correction was used to adjust $P$ values for multiple tests as needed. Additionally, this study defined the dominant and recessive genetic models as heterozygote+homozygote variant vs. homozygote wild and homozygote variant vs. heterozygote+homozygote wild, respectively.

\section{Results}

Main effect of individual TLR4 and MMP9 polymorphisms The distributions of studied genotypes of TLR4rs11536889, rs1927914 and MMP9rs17576 in the controls followed Hardy-Weinberg equilibrium (HWE) $(P>0.05)$ (Additional file 1: Table S1). As shown in Additional file 2: Table S2, there were no significant associations of TLR4 rs11536889 and rs1927914 polymorphisms with the risk of AA and its subtypes $(P>0.05)$ in the general and subgroup analysis stratified by AA location and size. MMP9rs17576 AA genotype was related to a higher risk of overall AA $(\mathrm{OR}=1.897, P=0.015)$, AAA $(\mathrm{OR}=2.291, P=0.007)$ or small AA $(\mathrm{OR}=1.977$, $P=0.024)$ compared with GG genotype. However, no significant link between MMP9rs17576 polymorphisms and the risk of TAA and large AA was observed $(P>0.05)$.

\section{Two-way interactions between polymorphisms of TLR4 and MMP9}

In the two-way interaction analyses with a combined genotype containing the most common SNP for each gene, the most significant interaction was between dominant genetic model of TLR4rs1927914 and recessive genetic model of MMP9rs17576 (Table 2). This interaction was linked to an increased risk of TAA $\left(P_{\text {interaction }}\right.$ $=0.038, \mathrm{OR}=6.186)$ and large AA $\left(P_{\text {interaction }}=0.044\right.$, $\mathrm{OR}=5.892$ ). In contrast, no statistically significant interaction was found among other SNP-SNP interactions $\left(P_{\text {interaction }}>0.05\right)$.

\section{Epistatic effects of two-way interactions between TLR4rs1927914 and MMP9rs17576}

We further investigated the epistatic effects between pairs of interacting factors, as shown in Table 3 and Table 4. For TLR4rs1927914 and MMP9rs17576, TC + CC genotype at rs1927914 and AA genotype at rs17576 each conferred an increased TAA risk $(\mathrm{OR}=6.329$ and 2.322, respectively) and large $\mathrm{AA}(\mathrm{OR}=6.554$ and 3.243 , respectively), but only if they were both present; rs17576 AA genotype was correlated with an increased risk of overall AA $(O R=2.333)$ and AAA $(O R=2.519)$, but only in the presence of TC + CC genotype at rs1927914.

\section{Cumulative effect of the interacting factors of TLR4rs1927914 and MMP9rs17576}

We also evaluated the cumulative effect among the polymorphism interaction between TLR4rs1927914 and MMP9rs17576. A dosage effect was significantly observed with an increase in the number of risk genotypes linked to an increased risk of overall AA $\left(P_{\text {trend }}=0.032\right)$ (Table 5) and AAA $\left(P_{\text {trend }}=0.031\right)$ (Table 6). However, other subtype of AA risk was not statistically increased while one or two mutation genotypes were present.

\section{Three-dimensional interactions among polymorphisms of TLR4 and MMP9 genes}

We further examined potential three-dimensional interactions among TLR4rs11536889, rs1927914 and MMP9rs17576, however, no statistical significance among three-dimensional interactions was observed in relation to the risk of overall AA (Table 7) and its subtypes (Additional file 3: Table S3). 


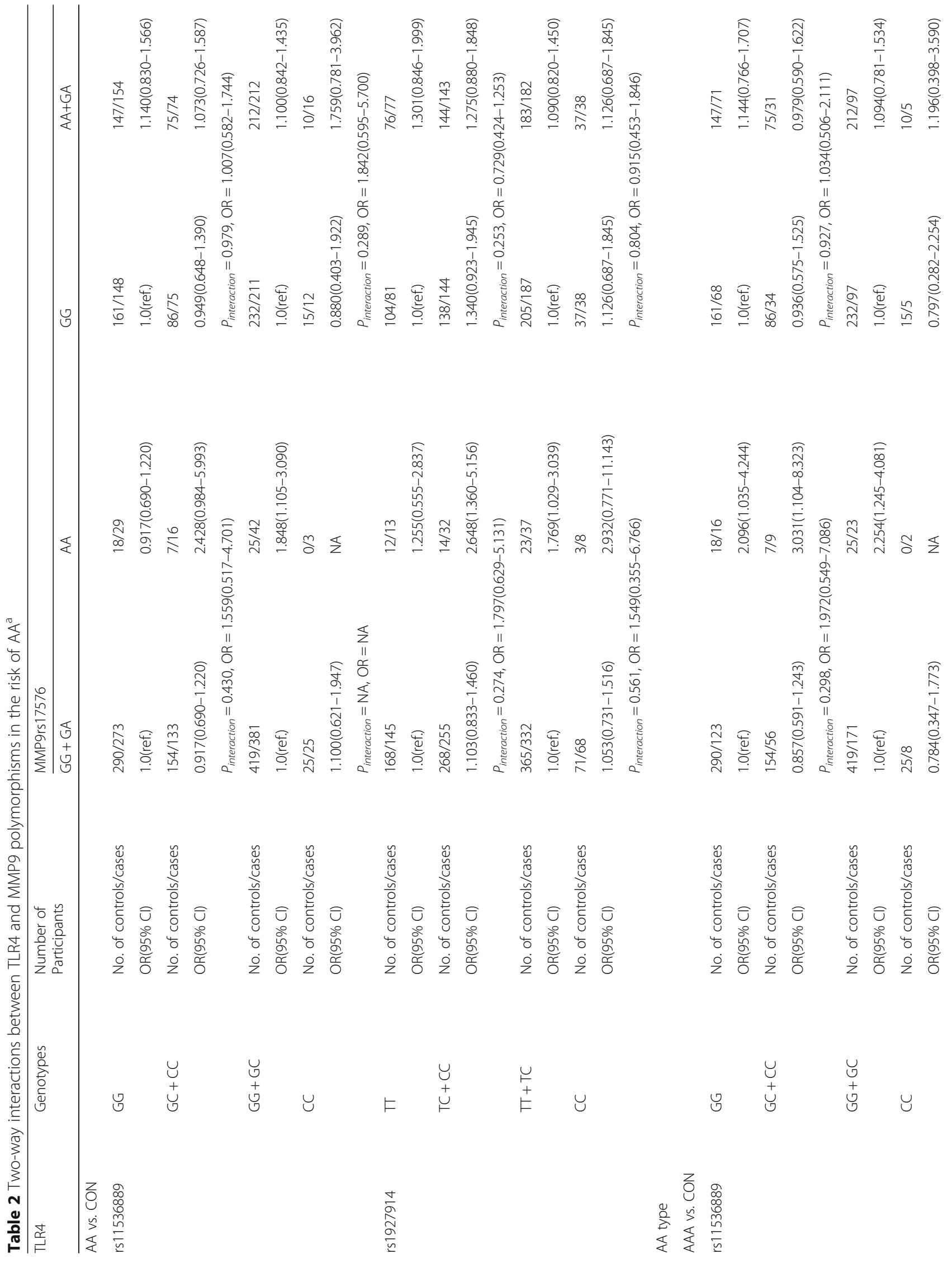




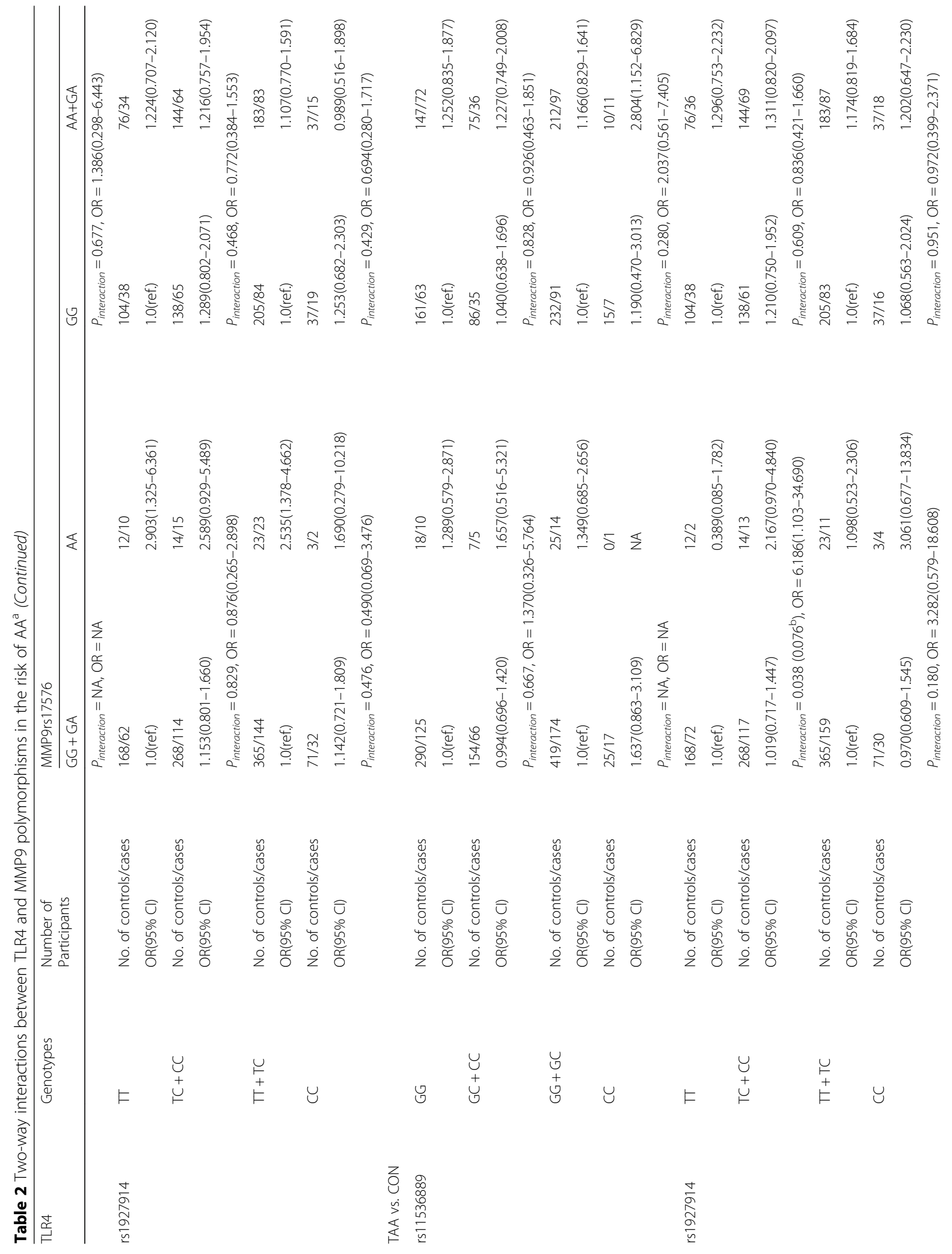




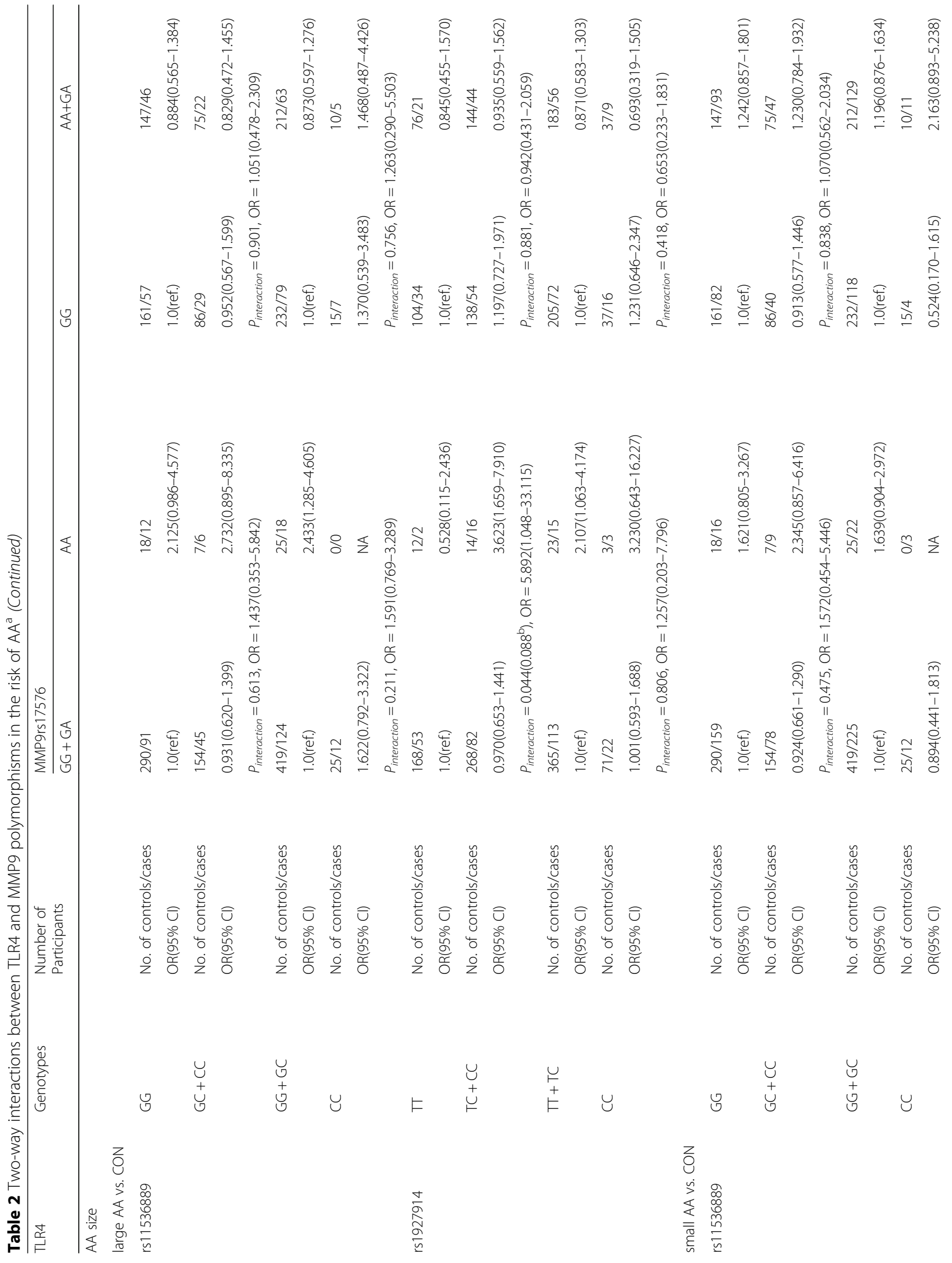


Li et al. BMC Cardiovascular Disorders $\quad$ (2019) 19:72

Page 7 of 11

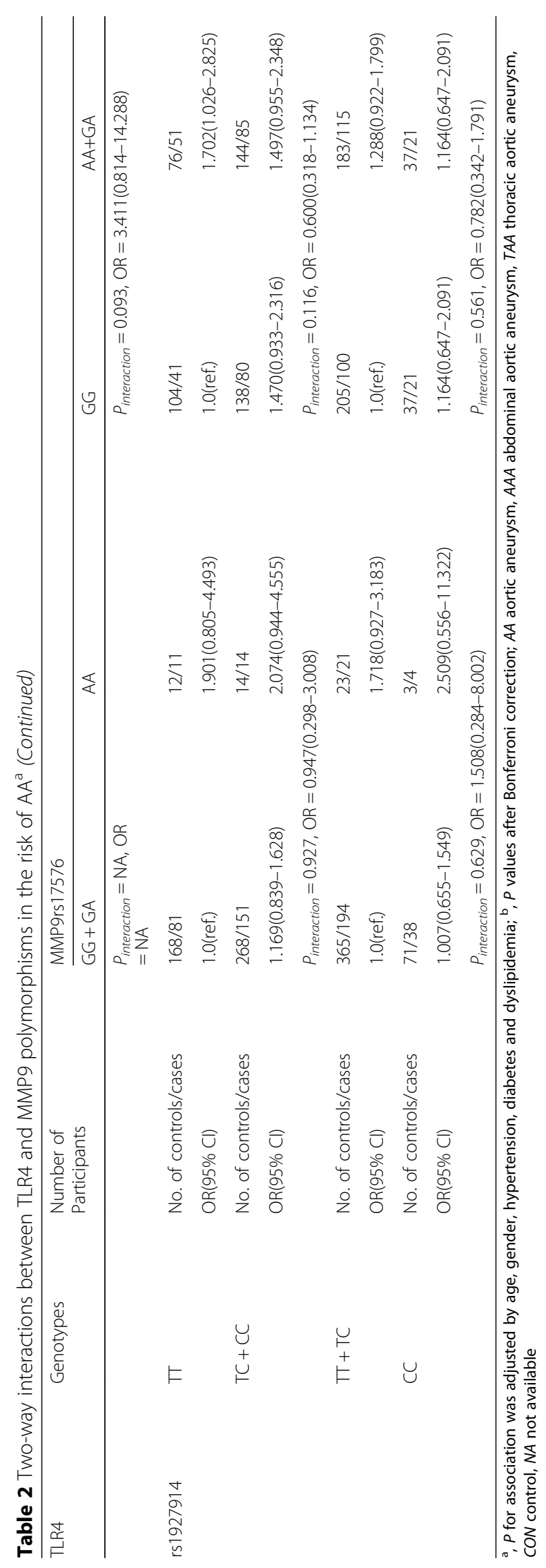


Table 3 Epistatic effect of pair-wise interacting factors of TLR4rs1927914 and MMP9rs17576 on overall AA risk ${ }^{a}$

\begin{tabular}{llll}
\hline Comparison & Subset & $P$ & OR(95\%Cl) \\
\hline TLR4rs1927914 & MMP9rs17576 & & \\
TC + CC vs. TT & GG + GA & 0.395 & $1.131(0.852-1.500)$ \\
& MMP9rs17576 & & \\
& AA & 0.160 & 2.150(0.740-6.246) \\
MMP9rs17576 & TLR4rs1927914 & & \\
AA vs. GG + GA & TT & 0.531 & $1.301(0.571-2.964)$ \\
& TLR4rs1927914 & & \\
& TC + CC & $0.011\left(0.022^{b}\right)$ & $2.333(1.213-4.488)$ \\
\hline
\end{tabular}

a, $P$ for association was adjusted by age, gender, hypertension, diabetes and dyslipidemia; ${ }^{b}, P$ values after Bonferroni correction

\section{Discussion}

Human genetic polymorphisms can be used to predict the presence of particular diseases. However, a substantial body of studies have concentrated on the identification of SNP responsible for disease risk, but they often found no or weak effects [20, 21]. Therefore, individual SNP association cannot adequately account for the causality of complex disease. Recently, researchers are focusing more attention on the potential combined interaction effects of SNPs in two or more loci, and the results have usually indicated a moderate or strong effect on disease risk [22, 23]. As the gate of inflammatory reaction, TLR4 can induce pathological aortic phenotype changes, such as outward vascular remodeling [24]. MMP9, as a multifunctional proteinase, is responsible for ECM degradation and weakening aortic wall [25]. Recently, Li et al. demonstrated the role of TLR4 signaling in the regulation of MMP9 expression in human aortic smooth muscle cells [26]. Qin et al. reported that the mice deficiency of TLR4 gene exhibited markedly decreased AngII-mediated AAA formation and MMP9 secretion, and TLR4 levels were elevated in human aneurysmal tissue
[27]. These data suggested that TLR4 pathway linked to MMP9 appeared to have a key role in AA pathophysiology, but the gene association study was lacking. To the best of our knowledge, this study is the first to evaluate the interaction effects of two tag-SNP rs11536889 and rs1927914 in TLR4 and one tag-SNP rs17576 in MMP9 on the risk of AA and its subtypes in a Chinese Han population.

TLR4rs11536889 is located in the 3'-UTR of, where a genetic change can influence the translation of mRNA [28]. SNP rs1927914 locates in the $5^{\prime}$-UTR of TLR4 and may influence transcriptional factor binding site and regulate the promoter activity [14]. TLR4rs11536889 and rs1927914 polymorphisms have been reported to be correlated with various inflammatory diseases [29-31]. Furthermore, SNP rs17576 is a coding variant in exon 6 of MMP9 leading to an amino acid substitution, which might increase the enzyme activity of MMP9 [32]. Some researchers have reported that MMP9rs17576 polymorphisms were associated with lung cancer [33], left ventricular dysfunction in coronary artery disease [34] and carotid artery intima-media thickness [35]. However, none of above three SNPs has been studied in AA disease by now. Compared with a SNP, a combination of two or more SNPs could generate synergistic or antagonistic effects, which would change the susceptibility to disease [36, 37]. Individually, TLR4rs11536889, rs1927914 and MMP9rs17576 had no effects on the risk of TAA and large AA. In the analysis of two-way interaction, the paired TLR4rs1927914-MMP9rs17576 polymorphism demonstrated obvious interaction effects with ORs of 6.186 and 5.892 for the risk of TAA and large AA, respectively. Our findings indicated their strong synergistic effects, which could alter the risk of an individual towards AA. This may partly interpret the epigenetic heritability loss of AA risk and indicate a novel insight into the multifactorial etiology of AA risk concerning inflammation-related

Table 4 Epistatic effect of pair-wise interacting factors of TLR4rs1927914 and MMP9rs17576 on the risk of AA subtypes ${ }^{a}$

\begin{tabular}{|c|c|c|c|c|c|c|c|c|c|}
\hline \multirow[b]{2}{*}{ Comparison } & \multirow[b]{2}{*}{ Subset } & \multicolumn{2}{|l|}{ AAA vs. CON } & \multicolumn{2}{|c|}{ TAA vs. CON } & \multicolumn{2}{|c|}{ large AA vs. CON } & \multicolumn{2}{|c|}{ small AA vs. CON } \\
\hline & & $P$ & $\mathrm{OR}(95 \% \mathrm{Cl})$ & $P$ & $\mathrm{OR}(95 \% \mathrm{Cl})$ & $P$ & OR(95\%Cl) & $P$ & OR(95\%Cl) \\
\hline TLR4rs1927914 & MMP9rs 17576 & & & & & & & & \\
\hline \multirow[t]{3}{*}{$\mathrm{TC}+\mathrm{CC}$ vs. TT } & $\mathrm{GG}+\mathrm{GA}$ & 0.244 & $\begin{array}{l}1.247 \\
(0.860-1.809)\end{array}$ & 0.940 & $\begin{array}{l}0.986 \\
(0.692-1.406)\end{array}$ & 0.902 & $\begin{array}{l}1.025 \\
(0.687-1.531)\end{array}$ & 0.357 & $\begin{array}{l}1.170 \\
(0.838-1.633)\end{array}$ \\
\hline & MMP9rs17576 & & & & & & & & \\
\hline & AA & 0.686 & $\begin{array}{l}1.266 \\
(0.403-3.985)\end{array}$ & $\begin{array}{l}0.041 \\
\left(0.082^{b}\right)\end{array}$ & $\begin{array}{l}6.329 \\
(1.077-37.184)\end{array}$ & $\begin{array}{l}0.032 \\
\left(0.064^{\mathrm{b}}\right)\end{array}$ & $\begin{array}{l}6.554 \\
(1.172-36.649)\end{array}$ & 0.736 & $\begin{array}{l}1.219 \\
(0.386-3.850)\end{array}$ \\
\hline MMP9rs17576 & TLR4rs1927914 & & & & & & & & \\
\hline \multirow[t]{3}{*}{$A A$ vs. $G G+G A$} & $\Pi T$ & 0.072 & $\begin{array}{l}2.258 \\
(0.929-5.489)\end{array}$ & 0.202 & $\begin{array}{l}0.369 \\
(0.080-1.706)\end{array}$ & 0.436 & $\begin{array}{l}0.542 \\
(0.116-2.528)\end{array}$ & 0.150 & $\begin{array}{l}1.890 \\
(0.794-4.496)\end{array}$ \\
\hline & TLR4rs1927914 & & & & & & & & \\
\hline & $\mathrm{TC}+\mathrm{CC}$ & $0.017\left(0.034^{b}\right)$ & $\begin{array}{l}2.519 \\
(1.177-5.389)\end{array}$ & $\begin{array}{l}0.038 \\
\left(0.076^{b}\right)\end{array}$ & $\begin{array}{l}2.322 \\
(1.047-5.150)\end{array}$ & $\begin{array}{l}0.003 \\
\left(0.006^{b}\right)\end{array}$ & $\begin{array}{l}3.243 \\
(1.488-7.068)\end{array}$ & 0.136 & $\begin{array}{l}1.795 \\
(0.832-3.872)\end{array}$ \\
\hline
\end{tabular}

${ }_{\text {a }} P$ for association was adjusted by age, gender, hypertension, diabetes and dyslipidemia; ${ }^{\mathrm{b}}, P$ values after Bonferroni correction; $A A$ aortic aneurysm, $A A A$ abdominal aortic aneurysm, TAA thoracic aortic aneurysm, CON control 
Table 5 Cumulative effect of the interacting factors of TLR4rs1927914-MMP9rs17576 on overall AA risk ${ }^{a}$

\begin{tabular}{llll}
\hline No. of interacting genotypes & Controls/cases & $P$ & $\mathrm{OR}(95 \% \mathrm{Cl})$ \\
\hline TLR4rs1927914-MMP9rs17576 & & & \\
0 & $168 / 145$ & & $1.0($ ref. $)$ \\
1 & $280 / 268$ & 0.381 & $1.134(0.856-1.500)$ \\
2 & $14 / 32$ & 0.005 & $2.609(1.336-5.097)$ \\
& & $P_{\text {trend }}=0.032$ \\
\hline
\end{tabular}

${ }^{a}, P$ for association was adjusted by age, gender, hypertension, diabetes and dyslipidemia

gene TLR4 and ECM degradation gene MMP9 pathways. Maximal aortic diameter has been found to link directly to the risk of aortic complications [38]. The phenomenon of an effect modification by maximal aortic diameter perceived in the TLR4 and MMP9 interaction may provide a crucial hint to help avoid AA complications by preventing diameter growth in susceptible people.

The epistatic effect of two or more genes can explain the missing heritability of many diseases, which is usually underestimated or even ignored [39]. The epistasis was more prominent than a single susceptible gene in terms of main effect, which implied the multipart interaction effect [23]. Many studies have suggested that epistatic gene-gene interactions offered susceptibility to a variety of cancer $[40,41]$. In fact, as a complex disease, only in rare cases does AA seem to be monogenic and, generally, multiple genes are involved in AA occurrence. However, different types of AA may have different genetic background and show varying sensitivity to the effects of genetic polymorphisms. In the present study, the most significant epistatic effect was between TLR4rs1927914 and MMP9rs17576. Both rs1927914 TC + CC genotype and rs17576 AA genotype were related to an increased risk of TAA and large AA. Moreover, AA genotype of rs 17576 conferred an increased risk of overall AA and AAA in the presence of TC + CC genotype of rs1927914 even after Bonferroni correction, which was a strict method for multiple comparisons. These observations revealed that the obviously epistatic effect of TLR4rs1927914 and MMP9rs17576 on the pathogenesis of AA might rely on the presence of the other SNP in each pair-wise interaction. However, the direct evidence for a specific functional association between TLR4 and MMP9 polymorphisms is scarce. Only one study by Ruvolo et al. in 2014 reported that TLR4rs4986790 polymorphism confers a higher susceptibility for TAA and it represents, together with ACErs1799752, MMP9rs3918242 and MMP2rs2285053 SNPs, an independent TAA risk factor [42]. Genetic variants of any gene within these networks could have a potential influence on the action of other genes and thus disrupt the balance of homeostasis.

In this study, the cumulative effect was found to be altered in overall AA and AAA. The dose effects suggested that overall AA risk was significantly increased when one or two risk genotypes were present $(\mathrm{OR}=1.134$ and 2.609, respectively). Meanwhile, AAA risk was significantly increased, while one or two risk genotypes were present (OR $=1.293$ and 2.736, respectively). The cumulative effect of the two SNPs was stronger than an individual SNP effect, which is indicative of a true interaction. However, we further analyzed the three-dimensional interaction effect of TLR4rs11536889-TLR4rs1927914-MMP9rs17576 on the risk of AA and its subtypes, but no interaction effect was shown among them. This may possibly attribute to our relatively small sample size and some scarce genotypes.

Our study has several limitations. First, this study was performed among a preselected population, thus the results may be affected by selection bias. Second, the sample size was relatively small and should be enlarged to confirm the results of the interaction effects, especially for rare genotypes. Third, complete lifestyle information (i.e. smoking and drinking status) was lost, precluding their use as potential environmental factors in our multivariate logistic regression. In addition, since we only tested two TLR4 SNPs and one MMP9 SNP in this study, comprehensive studies involving more functional SNPs should be conducted to perform a multiple testing correction in the future.

Table 6 Cumulative effect of the interacting factors of TLR4rs1927914-MMP9rs17576 on the risk of AA subtypes ${ }^{a}$

\begin{tabular}{|c|c|c|c|c|c|c|c|c|c|c|c|c|}
\hline \multirow{2}{*}{$\begin{array}{l}\text { No. of } \\
\text { interacting } \\
\text { genotypes }\end{array}$} & \multicolumn{3}{|l|}{ AAA } & \multicolumn{3}{|l|}{ TAA } & \multicolumn{3}{|l|}{ large AA } & \multicolumn{3}{|l|}{ small AA } \\
\hline & $\begin{array}{l}\text { Controls/ } \\
\text { cases }\end{array}$ & $P$ & $\mathrm{OR}(95 \% \mathrm{Cl})$ & $\begin{array}{l}\text { Controls/ } \\
\text { cases }\end{array}$ & $P$ & $\mathrm{OR}(95 \% \mathrm{Cl})$ & $\begin{array}{l}\text { Controls/ } \\
\text { cases }\end{array}$ & $P$ & $\mathrm{OR}(95 \% \mathrm{Cl})$ & $\begin{array}{l}\text { Controls/ } \\
\text { cases }\end{array}$ & $P$ & $\mathrm{OR}(95 \% \mathrm{Cl})$ \\
\hline \multicolumn{13}{|c|}{ TLR4rs1927914-MMP9rs17576 } \\
\hline 0 & $168 / 62$ & & 1.0(ref.) & $168 / 72$ & & 1.0(ref.) & $168 / 53$ & & 1.0(ref.) & $168 / 81$ & & 1.0(ref.) \\
\hline 1 & $280 / 124$ & 0.170 & $\begin{array}{l}1.293 \\
(0.896-1.865)\end{array}$ & $280 / 119$ & 0.808 & $\begin{array}{l}0.957 \\
(0.673-1.362)\end{array}$ & 280/84 & 0.001 & $\begin{array}{l}1.002 \\
(0.673-1.492)\end{array}$ & $280 / 162$ & 0.287 & $\begin{array}{l}1.196 \\
(0.860-1.664)\end{array}$ \\
\hline \multirow[t]{2}{*}{2} & $14 / 15$ & 0.014 & $\begin{array}{l}2.736 \\
(1.222-6.128)\end{array}$ & $14 / 13$ & 0.058 & $\begin{array}{l}2.180 \\
(0.973-4.886)\end{array}$ & $14 / 16$ & 0.004 & $\begin{array}{l}3.234 \\
(1.456-7.184)\end{array}$ & $14 / 14$ & 0.072 & $\begin{array}{l}2.060 \\
(0.936-4.533)\end{array}$ \\
\hline & & \multicolumn{2}{|c|}{$P_{\text {trend }}=0.031$} & & \multicolumn{2}{|c|}{$P_{\text {trend }}=0.338$} & & \multicolumn{2}{|c|}{$P_{\text {trend }}=0.079$} & & \multicolumn{2}{|c|}{$P_{\text {trend }}=0.084$} \\
\hline
\end{tabular}

a $P$ for association was adjusted by age, gender, hypertension, diabetes and dyslipidemia; $A A$ aortic aneurysm, $A A A$ abdominal aortic aneurysm, $T A A$ thoracic aortic aneurysm 
Table 7 The three-dimensional interactions of the MMP9rs17576-TLR4rs11536889-TLR4rs1927914 with overall AA risk ${ }^{a}$

\begin{tabular}{|c|c|c|c|c|}
\hline SNP genotypes & & & $P$ & $\mathrm{OR}(95 \% \mathrm{Cl})$ \\
\hline \multicolumn{5}{|c|}{ MMP9rs17576-TLR4rs11536889-TLR4rs1927914 } \\
\hline $\mathrm{GG}+\mathrm{GA}$ & GG & $\pi$ & & 1 (ref) \\
\hline $\mathrm{GG}+\mathrm{GA}$ & GG & $\mathrm{TC}+\mathrm{CC}$ & 0.294 & $1.230(0.836-1.810)$ \\
\hline $\mathrm{GG}+\mathrm{GA}$ & $\mathrm{GC}+\mathrm{CC}$ & $\pi$ & 0.594 & $1.130(0.721-1.773)$ \\
\hline$G G+G A$ & $\mathrm{GC}+\mathrm{CC}$ & $\mathrm{TC}+\mathrm{CC}$ & 0.942 & $0.982(0.594-1.622)$ \\
\hline AA & GG & $\pi$ & 0.844 & $0.887(0.268-2.932)$ \\
\hline AA & GG & $\mathrm{TC}+\mathrm{CC}$ & 0.013 & $2.710(1.232-5.959)$ \\
\hline AA & $\mathrm{GC}+\mathrm{CC}$ & $\pi$ & 0.152 & $2.484(0.715-8.635)$ \\
\hline \multirow[t]{2}{*}{ AA } & $\mathrm{GC}+\mathrm{CC}$ & $\mathrm{TC}+\mathrm{CC}$ & 0.086 & $3.312(0.843-13.012)$ \\
\hline & & & \multicolumn{2}{|c|}{$P_{\text {interaction }}=0.696, \mathrm{OR}=0.629(0.061-6.451)$} \\
\hline
\end{tabular}

${ }^{a}, P$ for association was adjusted by age, gender, hypertension, diabetes and dyslipidemia

\section{Conclusions}

In summary, we discovered novel SNP interactions among TLR4 and MMP9 which modified the AA risk, and our study was the first to show that the pairwise interacting TLR4rs1927914-MMP9rs17576 combinations were related to increased TAA and large AA risk. Furthermore, TLR4rs1927914 and MMP9rs17576 polymorphisms showed an epistatic effect when present together on the risk of AA and its subtypes, and these two-way interactions had dose effects on overall AA and AAA risk. TLR4rs1927914 might have greater efficiency when combined with MMP9rs17576 for AA risk than a single SNP on its own. Further functional and molecular experiments should deserve special attention to clarify the interaction effect of susceptible genes, which could provide an important clue for the etiology and perhaps effective treatment of AA.

\section{Additional files}

Additional file 1: Table S1. The genotype frequencies and HWE in this study. (DOCX $16 \mathrm{~kb}$ )

Additional file 2: Table S2. The association of TLR4 and MMP9 polymorphisms with the risk of AA and its subtypes. ${ }^{a}$. (DOCX $18 \mathrm{~kb}$ )

Additional file 3: Table S3. The three dimensions interactions of the MMP9rs17576-TLR4rs11536889-TLR4rs1927914 with the risk of AA subtypes ${ }^{\mathrm{a}}$. (DOCX $\left.19 \mathrm{~kb}\right)$

\section{Abbreviations}

AA: Aortic aneurysm; AAA: Abdominal aortic aneurysm; Cl: Confidence interval; CTA: Computed tomography angiography; DBP: Diastolic blood pressure; ECM: Extracellular matrix; FPG: Fasting serum glucose; HDL-C: Highdensity lipoprotein cholesterol; HWE: Hardy-Weinberg equilibrium; LDLC: Low-density lipoprotein cholesterol; MMP9: Matrix metalloproteinase 9; OR: Odds ratio; SBP: Systolic blood pressure; SNP: Single nucleotide polymorphism; TAA: Thoracic aortic aneurysm; TC: Total cholesterol; TG: Triglyceride; TLR4: Toll-like receptor 4; UTR: Untranslated region

\section{Acknowledgments}

The authors thank Shi-jie Xin, Jian Zhang and Zhi Lv for their assistance.

\section{Funding}

This work was supported by grants from the 13th five years for the National Key Research and Development Program \& Key Special Project (2017YFC0907400). The funder had no role in the data analysis and manuscript preparation

\section{Availability of data and materials}

The datasets generated and/or analyzed during the current study are available from the corresponding author on reasonable request.

\section{Authors' contributions}

$\mathrm{TL}$ performed the DNA extraction, analyzed data and drafted the manuscript. XZ and LS contributed to statistical analysis. XTL and HYS participated in the sample collection. JY participated in the study design. YY designed the research and revised the manuscript. All authors have read and approved the final manuscript

\section{Ethics approval and consent to participate}

The study was approved by the Ethics Committee of the First Hospital of China Medical University. Written informed consent was obtained from each participant.

\section{Consent for publication}

Not applicable.

\section{Competing interests}

The authors declare that they have no competing interests.

\section{Publisher's Note}

Springer Nature remains neutral with regard to jurisdictional claims in published maps and institutional affiliations.

\section{Author details \\ ${ }^{1}$ Tumor Etiology and Screening Department of Cancer Institute and General Surgery, The First Hospital of China Medical University, No.155 Nanjing Bei Street, Heping District, Shenyang, Liaoning Province, People's Republic of China 1 10001. '2Department of Cardiovascular Ultrasound, the First Hospital of China Medical University, Shenyang 110001, China. ${ }^{3}$ Medical Administration Department, the First Hospital of China Medical University, Shenyang 110001, China. ${ }^{4}$ Department of Vascular and Thyroid Surgery, the First Hospital of China Medical University, Shenyang 110001, China.}

Received: 4 July 2018 Accepted: 15 March 2019

Published online: 29 March 2019

\section{References}

1. Erbel R, Aboyans V, Boileau C, Bossone E, Bartolomeo RD, Eggebrecht H, Evangelista A, Falk V, Frank H, Gaemperli O, et al. 2014 ESC guidelines on the diagnosis and treatment of aortic diseases: document 
covering acute and chronic aortic diseases of the thoracic and abdominal aorta of the adult. The task force for the diagnosis and treatment of aortic diseases of the European Society of Cardiology (ESC). Eur Heart J. 2014;35(41):2873-926.

2. Guo DC, Papke CL, He R, Milewicz DM. Pathogenesis of thoracic and abdominal aortic aneurysms. Ann N Y Acad Sci. 2006;1085:339-52.

3. Tomee SM, Gebhardt WA, de Vries JP, Hamelinck VC, Hamming JF, Lindeman JH. Patients' perceptions of conservative treatment for a small abdominal aortic aneurysm. Patient Prefer Adherence. 2018;12:119-28.

4. Geisbusch S, Stefanovic A, Schray D, Oyfe I, Lin HM, Di Luozzo G, Griepp RB. A prospective study of growth and rupture risk of small-to-moderate size ascending aortic aneurysms. J Thorac Cardiovasc Surg. 2014;147(1):68-74.

5. Kuivaniemi H, Platsoucas CD, Tilson MD 3rd. Aortic aneurysms: an immune disease with a strong genetic component. Circulation. 2008;117(2):242-52.

6. Cowan JA Jr, Dimick JB, Henke PK, Rectenwald J, Stanley JC, Upchurch GR Jr. Epidemiology of aortic aneurysm repair in the United States from 1993 to 2003. Ann N Y Acad Sci. 2006;1085:1-10.

7. Raffort J, Lareyre F, Clement M, Hassen-Khodja R, Chinetti G, Mallat Z. Diabetes and aortic aneurysm: current state of the art. Cardiovasc Res. 2018;114(13):1702-13.

8. Wierzba W, Sliwczynski A, Pinkas J, Jawien A, Karnafel W. Diabetes mellitus increases the risk of ruptured abdominal aortic aneurysms. Diab Vasc Dis Res. 2017;14(5):463-4.

9. Kutikhin AG. Impact of toll-like receptor 4 polymorphisms on risk of cancer. Hum Immunol. 2011;72(2):193-206

10. Balistreri CR. Genetic contribution in sporadic thoracic aortic aneurysm? Emerging evidence of genetic variants related to TLR-4-mediated signaling pathway as risk determinants. Vasc Pharmacol. 2015;74:1-10.

11. Pisano C, Balistreri CR, Ricasoli A, Ruvolo G. Cardiovascular disease in ageing: an overview on thoracic aortic aneurysm as an emerging inflammatory disease. Mediat Inflamm. 2017;2017:1274034

12. Vorkapic E, Lundberg AM, Mayranpaa MI, Eriksson P, Wagsater D. TRIF adaptor signaling is important in abdominal aortic aneurysm formation. Atherosclerosis. 2015;241(2):561-8.

13. Buraczynska M, Zukowski P, Ksiazek K, Wacinski P, Dragan M. The effect of toll-like receptor 4 gene polymorphism on vascular complications in type 2 diabetes patients. Diabetes Res Clin Pract. 2016;1 16:7-13.

14. Zhang K, Zhou B, Wang Y, Rao L, Zhang L. The TLR4 gene polymorphisms and susceptibility to cancer: a systematic review and meta-analysis. Eur J Cancer. 2013:49(4):946-54.

15. Jiao Y, Zhao J, Hu B, La X, Gong X, Huang Y, Cai X, Zhang Y. Toll-like receptor 4 gene is associated with recurrent spontaneous miscarriage in Uygur and Han women in Xinjiang. Exp Ther Med. 2016;12(5):3268-74.

16. Bucci M, Vellecco V, Harrington L, Brancaleone V, Roviezzo F, Mattace Raso G, lanaro A, Lungarella G, De Palma R, Meli R, et al. Cross-talk between tolllike receptor 4 (TLR4) and proteinase-activated receptor 2 (PAR(2)) is involved in vascular function. Br J Pharmacol. 2013;168(2):411-20.

17. Rodriguez-Pla A, Beaty TH, Savino PJ, Eagle RC Jr, Seo P, Soloski MJ. Association of a nonsynonymous single-nucleotide polymorphism of matrix metalloproteinase 9 with giant cell arteritis. Arthritis Rheum. 2008;58(6):1849-53.

18. Sfar S, Saad H, Mosbah F, Chouchane L. Combined effects of the angiogenic genes polymorphisms on prostate cancer susceptibility and aggressiveness. Mol Biol Rep. 2009;36(1):37-45.

19. He C, Tu H, Sun L, Xu Q, Li P, Gong Y, Dong N, Yuan Y. Helicobacter pylori-related host gene polymorphisms associated with susceptibility of gastric carcinogenesis: a two-stage case-control study in Chinese. Carcinogenesis. 2013;34(7):1450-7.

20. Li T, Ren Z, Deng Y, Wang Y, Zhou H. Lack of association between RAD50IL13 polymorphisms and pediatric asthma susceptibility in northeastern Han Chinese. J Asthma. 2016;53(2):114-8.

21. Wang JY, Shyur SD, Lam FW, Wu LS. Polymorphisms of EHF-ELF5 genomic region and its association with pediatric asthma in the Taiwanese population. J Microbiol Immunol Infect. 2016;49(6):879-84.

22. Xu Q, Liu JW, He CY, Sun LP, Gong YH, Jing JJ, Xing CZ, Yuan Y. The interaction effects of pri-let-7a-1 rs10739971 with PGC and ERCC6 gene polymorphisms in gastric cancer and atrophic gastritis. PLoS One. 2014;9(2):e89203.

23. He C, Tu H, Sun L, Xu Q, Gong Y, Jing J, Dong N, Yuan Y. SNP interactions of helicobacter pylori-related host genes PGC, PTPN11, IL1B, and TLR4 in susceptibility to gastric carcinogenesis. Oncotarget. 2015;6(22):19017-26.

24. Hollestelle SC, De Vries MR, Van Keulen JK, Schoneveld AH, Vink A, Strijder CF, Van Middelaar BJ, Pasterkamp G, Quax PH, De Kleijn DP. Toll-like receptor 4 is involved in outward arterial remodeling. Circulation. 2004; 109(3):393-8.

25. Parks WC, Wilson CL, Lopez-Boado YS. Matrix metalloproteinases as modulators of inflammation and innate immunity. Nat Rev Immunol. 2004; 4(8):617-29

26. Li H, Xu H, Liu S. Toll-like receptors 4 induces expression of matrix metalloproteinase-9 in human aortic smooth muscle cells. Mol Biol Rep. 2011;38(2):1419-23.

27. Qin Z, Bagley J, Sukhova G, Baur WE, Park HJ, Beasley D, Libby P, Zhang Y, Galper JB. Angiotensin II-induced TLR4 mediated abdominal aortic aneurysm in apolipoprotein E knockout mice is dependent on STAT3. J Mol Cell Cardiol. 2015;87:160-70.

28. Sato K, Yoshimura A, Kaneko T, Ukai T, Ozaki Y, Nakamura H, Li X, Matsumura H, Hara Y, Ogata Y. A single nucleotide polymorphism in 3'untranslated region contributes to the regulation of toll-like receptor 4 translation. J Biol Chem. 2012;287(30):25163-72.

29. Song J, Kim DY, Kim CS, Kim HJ, Lee DH, Lee HM, Ko W, Lee G. The association between toll-like receptor 4 (TLR4) polymorphisms and the risk of prostate cancer in Korean men. Cancer Genet Cytogenet. 2009;190(2):88-92.

30. Xu Y, Jiang Z, Huang J, Meng Q, Coh P, Tao L. The association between toll-like receptor 4 polymorphisms and diabetic retinopathy in Chinese patients with type 2 diabetes. Br J Ophthalmol. 2015;99(9):1301-5.

31. Wang $\mathrm{X}, \mathrm{Xu} \mathrm{Z}$, Miao CH. Pooled analysis of association between a genetic variant in the 3 --untranslated region of toll-like receptor 4 and cancer risk. Genet Mol Res. 2015;14(4):17847-55.

32. Natividad A, Cooke G, Holland MJ, Burton MJ, Joof HM, Rockett K Kwiatkowski DP, Mabey DC, Bailey RL. A coding polymorphism in matrix metalloproteinase 9 reduces risk of scarring sequelae of ocular chlamydia trachomatis infection. BMC Med Genet. 2006;7:40.

33. Hu Z, Huo X, Lu D, Qian J, Zhou J, Chen Y, Xu L, Ma H, Zhu J, Wei Q, et al. Functional polymorphisms of matrix metalloproteinase-9 are associated with risk of occurrence and metastasis of lung cancer. Clin Cancer Res. 2005: 11(15):5433-9.

34. Mishra A, Srivastava A, Mittal T, Garg N, Mittal B. Association of matrix metalloproteinases (MMP2, MMP7 and MMP9) genetic variants with left ventricular dysfunction in coronary artery disease patients. Clin Chim Acta. 2012:413(19-20):1668-74.

35. Armstrong C, Abilleira S, Sitzer M, Markus HS, Bevan S. Polymorphisms in MMP family and TIMP genes and carotid artery intima-media thickness. Stroke. 2007;38(11):2895-9.

36. Liu L, Wu J, Zhong R, Wu C, Zou L, Yang B, Chen W, Zhu B, Duan S, Yu D, et al. Multi-loci analysis reveals the importance of genetic variations in sensitivity of platinum-based chemotherapy in non-small-cell lung cancer. Mol Carcinog. 2013;52(12):923-31.

37. Lin HY, Amankwah EK, Tseng TS, Qu X, Chen DT, Park JY. SNP-SNP interaction network in angiogenesis genes associated with prostate cancer aggressiveness. PLoS One. 2013;8(4):e59688.

38. Kim JB, Kim K, Lindsay ME, MacGillivray T, Isselbacher EM, Cambria RP, Sundt TM 3rd. Risk of rupture or dissection in descending thoracic aortic aneurysm. Circulation. 2015;132(17):1620-9.

39. Carlborg O, Haley CS. Epistasis: too often neglected in complex trait studies? Nat Rev Genet. 2004;5(8):618-25.

40. Aminimoghaddam S, Shahrabi-Farahani M, Mohajeri-Tehrani M, Amiri $P$, Fereidooni F, Larijani B, Shafiee G, Amoli MM. Epistatic interaction between adiponectin and survivin gene polymorphisms in endometrial carcinoma. Pathol Res Pract. 2015;211(4):293-7.

41. Chu M, Zhang R, Zhao Y, Wu C, Guo H, Zhou B, Lu J, Shi Y, Dai J, Jin G, et al. A genome-wide gene-gene interaction analysis identifies an epistatic gene pair for lung cancer susceptibility in Han Chinese. Carcinogenesis. 2014;35(3):572-7.

42. Ruvolo G, Pisano C, Candore G, Lio D, Palmeri C, Maresi E, Balistreri CR. Can the TLR-4-mediated signaling pathway be "a key inflammatory promoter for sporadic TAA"? Mediat Inflamm. 2014;2014:349476. 